\title{
MONITORAMENTO E AVALIAÇÃO NOS PLANOS MUNICIPAIS DE EDUCAÇÃO DE SÃO PAULO
}

\author{
Monitoring and evaluation in the municipal education plans of São Paulo
}

Monitoreo y evaluación en los planes municipales de educación de São Paulo

\begin{abstract}
Silvio Cesar Nunes Militão*
Maria Alice de Miranda Aranda**
\end{abstract}

\section{Resumo}

Fruto de pesquisa de pós-doutoramento, o presente artigo teve como objetivo precípuo analisar se/como as ações atinentes ao monitoramento e avaliação estão previstas nos Planos Municipais de Educação (PMEs) de um grupo de municipalidades do estado de São Paulo. Metodologicamente, ancorado na abordagem qualitativa, valeu-se de pesquisa bibliográfica e documental. O estudo revelou, inicialmente, que o processo de elaboração/aprovação dos PMEs mostrou-se exitoso ao atingir sua universalização na área geográfica investigada. $\mathrm{Na}$ sequência, evidenciou o lugar de destaque ocupado pelo monitoramento e avaliação no conjunto dos documentos perscrutados, com substancial protagonismo do Conselho Municipal de Educação e Secretaria Municipal de Educação na condução compartilhada do concernente processo. Não obstante, a partir das fontes documentais reunidas e analisadas, também constatou-se que permanece ainda o desafio de se contemplar um maior envolvimento da sociedade e dos múltiplos canais representativos, a exemplo do Fórum Municipal de Educação, nas questões referentes ao planejamento e gestão da educação municipal, a fim de que esta possa plenamente alcançar a tão almejada gestão democrática e a qualidade social.

PALAVRAS-CHAVE: Planos Municipais de Educação. Monitoramento e Avaliação. São Paulo.

\begin{abstract}
As a result of postdoctoral research, this article aimed to analyze whether/how the actions related to monitoring and evaluation are foreseen in the Municipal Education Plans (PMEs) of a group of municipalities in the state of São Paulo. Methodologically, anchored in the qualitative approach, it used bibliographic and documentary research. Initially, the study revealed that the process of preparation/approval of PMEs proved successful in achieving their universalization in the geographic area investigated. Then, it highlighted the prominent place occupied by monitoring and evaluation in the set of documents examined, with substantial protagonism of the Municipal Council of Education and the Municipal Secretariat

\footnotetext{
* Doutor em Educação pela Universidade Estadual Paulista (UNESP). Professor Assistente vinculado à PósGraduação em Educação- Departamento de Didática da Faculdade de Filosofia e Ciências/Universidade Estadual Paulista (FFC/UNESP). Líder do Grupo de Estudos e Pesquisas em Políticas Educacionais e Práticas Educativas - GEPPOPE. Pós-doutorando na Linha de Pesquisa "Políticas e Gestão da Educação" do PPGEdu da UFGD, sob a supervisão da Profa. Dra. Maria Alice de Miranda Aranda. E-mail: scnmilitao@gmail.com.

** Doutora em Educação pela Universidade Federal de Mato Grosso do Sul (UFMS). Professora Associada da Faculdade de Educação na Universidade Federal da Grande Dourados, vinculada à Pós-Graduação em Educação (FAED/UFGD). Líder do Grupo de Pesquisa GEPGE/UFGD. Instituição: Universidade Federal da Grande Dourados (UFGD). Cidade: Dourados/MS. País: Brasil. E-mail: mariaalicearanda@gmail.com.
} 
of Education in the shared conduct of the concerned process. However, from the documentary sources gathered and analyzed, it was also found that the challenge remains to contemplate greater involvement of society and the multiple representative channels, such as the Municipal Education Forum, in matters related to planning and management. municipal education so that it can fully achieve the long-awaited democratic management and social quality.

KEYWORDS: Municipal Education Plans. Monitoring and Evaluation. São Paulo.

\section{Resumen}

Como resultado de la investigación postdoctoral, este artículo tuvo como objetivo analizar si/como se prevén las acciones relacionadas con el monitoreo y la evaluación en los Planes de Educación Municipales (PMEs) de un grupo de municipios en el estado de São Paulo. Metodológicamente, anclado en el enfoque cualitativo, utilizó la investigación bibliográfica y documental. Inicialmente, el estudio reveló que el proceso de preparación/aprobación de las PMEs resultó exitoso en lograr su universalización en el área geográfica investigada. Luego, destacó el lugar destacado ocupado por el monitoreo y la evaluación en el conjunto de documentos examinados, con protagonismo sustancial del Consejo Municipal de Educación y la Secretaría Municipal de Educación en la conducta compartida del proceso en cuestión. Sin embargo, a partir de las fuentes documentales reunidas y analizadas, también se encontró que el desafío sigue siendo contemplar una mayor participación de la sociedad y los múltiples canales representativos, como el Foro Municipale de Educación, en asuntos relacionados con la planificación y la gestión. educación municipal para que pueda alcanzar plenamente la tan esperada gestión democrática y la calidad social.

PALABRAS CLAVE: Planes Municipales de Educación. Monitoreo y Evaluación. São Paulo.

\section{INTRODUÇÃO}

A Lei $n^{\circ}$ 13.005/2014, que instituiu o Plano Nacional de Educação (PNE) vigente, determinou em seu artigo $8^{\circ}$ que todos os entes federativos subnacionais elaborassem seus respectivos Planos de Educação no prazo de um ano a partir da sua publicação (ou seja, até o dia 24 de junho de 2015), resultando numa inédita (quase) universalização dos planos educacionais infranacionais (ALVES, 2017; OLIVEIRA et al, 2016).

Conforme informações disponibilizadas pela página ${ }^{1}$ do Ministério da Educação (MEC) denominada "PNE em Movimento - Situação dos Planos de Educação", das 27 unidades da Federação, incluindo-se o Distrito Federal, 26 (ou 96,3\%) possuem Planos de Educação sancionados por lei e apenas um (ou 3,7\%) único estado (Rio de Janeiro) ainda não converteu seu correspondente plano em norma jurídica. Dos 5.570 municípios brasileiros, enquanto 5.568 (ou 99,96\%) deles já aprovaram seus respectivos Planos na forma da Lei, somente 2 (ou $0,04 \%$ ) ainda não o fizeram (Iaras e Ribeirão Preto, ambos do estado de São Paulo).

No caso do estado de São Paulo², especificamente, dos 645 municípios integrantes: 643 (ou 99,7\%) já possuem Planos Municipais de Educação (PMEs) aprovados por lei municipal, enquanto que em outros 2 (ou $0,3 \%$ ) o Projeto de Lei referente ao respectivo PME encontra-se no Poder Legislativo local aguardando aprovação.

\footnotetext{
${ }^{1}$ Trata-se da página criada pelo MEC para acompanhar a situação dos Planos de Educação do país, disponível em: <http://pne.mec.gov.br/planos-de-educacao/situacao-dos-planos-de-educacao> e acessada em 10/07/2019.

${ }^{2}$ Em São Paulo, o Plano Estadual de Educação foi aprovado pela Lei no 16.279 , de 8 de julho de 2016, contendo 11 artigos, 21 metas e 262 estratégias.
}

Educação e Fronteiras On-Line, Dourados/MS, v.9, n.27, p.129-140, set. /dez. 2019 
Diante de tal quadro, estados, Distrito Federal e municípios deparam-se, na atualidade, com o crucial desafio de implementar, monitorar e avaliar tais planos, tal qual demandado pelos artigos $5^{\circ}$ e $7^{\circ}$ da Lei $n^{\circ} 13.005 / 2014$ (ANTUNES, 2019; DOURADO; GROSSI JÚNIOR; FURTADO, 2016; NASCIMENTO; GROSSI JÚNIOR; PEREIRA, 2017; SCAFF; OLIVEIRA, 2018).

Frente ao exposto, questiona-se: qual o "lugar" do monitoramento e avaliação nos PMEs das municipalidades jurisdicionadas à Região Administrativa de Marília, mais adiante elencadas.

Fruto de uma pesquisa mais ampla desenvolvida em nível de pós-doutoramento ${ }^{3}$, o artigo tem, portanto, como objetivo precípuo analisar se/como as ações atinentes ao monitoramento e avaliação estão previstas nos PMEs das localidades que compõem a Região Administrativa de Marília.

Afora esta introdução, que apresenta a temática e o objetivo do trabalho em tela, o artigo está estruturado em quatro seções. A primeira seção demonstra o percurso metodológico concernente ao desenvolvimento do estudo proposto. A seção subsequente apresenta o cenário de aprovação e vigência dos PMEs de municipalidades pertencentes ao centro-oeste paulista. A terceira seção analisa o "lugar" do monitoramento e avaliação nos PMEs dos municípios contemplados pelo presente estudo. A última seção, por sua vez, apresenta as considerações finais.

\section{Procedimentos metodológicos do estudo}

Tendo em vista a consecução do objetivo proposto, o estudo desenvolvido ancorou-se em uma abordagem qualitativa (LÜDKE; ANDRÉ, 1986) e contemplou os seguintes procedimentos metodológicos: pesquisa bibliográfica e documental.

Inicialmente realizada, a pesquisa bibliográfica consistiu no levantamento e análise “[...] de toda a bibliografia já publicada [...]" (MARCONI; LAKATOS, 2011, p. 43) acerca da temática em abordagem, propiciando a construção do referencial teórico da pesquisa e subsidiando a posterior e concernente análise dos dados empíricos coletados.

$\mathrm{Na}$ sequência, foi desenvolvida a pesquisa documental cujo corpus de análise abrangeu primordialmente os Planos de Educação de municípios pertencentes à Região Administrativa de Marília, além de dois documentos de âmbito federal: PNE 2014-2024 e Caderno de Orientações para elaboração dos PMEs.

Para coleta das leis de criação e correspondentes anexos (planos propriamente ditos, com as respectivas metas e estratégias fixadas) dos PMEs das municipalidades abrangidas pela região selecionada pelo estudo em tela, recorreu-se primeiramente a já referida página "PNE em Movimento - Situação dos Planos de Educação", na qual obteve-se acesso a 29 PMEs completos (dueto lei e anexo). ${ }^{4}$

\footnotetext{
${ }^{3}$ Trata-se da pesquisa intitulada "Monitoramento do Planos Decenais de Educação na Região Administrativa de Marília (SP)”, voltada ao mapeamento e análise dos mecanismos de implementação, monitoramento e avaliação dos Planos Municipais de Educação (PMEs) jurisdicionados à Região supracitada, desenvolvida em nível de pósdoutoramento junto ao Programa de Pós-Graduação em Educação da Universidade Federal da Grande Dourados (PPGEdu/UFGD), financiada pelo Programa Nacional de Pós-Doutorado (PNPD/CAPES).

${ }^{4}$ Em relação aos outros 22 municípios restantes, só estava disponível na página do MEC apenas a lei de criação do PME, desprovida do anexo correspondente.
} 
Portanto, na sequência, realizou-se consultas por meio da internet aos sites das respectivas Câmaras Municipais, Prefeituras e Secretarias Municipais de Educação (ou órgão equivalente) para obtenção de mais PMEs completos, o que resultou em 35 planos coletados.

Adicionalmente, como nem todas as cidades mantinham disponíveis pública e eletronicamente (na internet) seus PMEs para consulta/download, fez-se necessário, ainda, solicitar às municipalidades restantes via $e$-mail tais documentos, totalizando um universo de 39 (ou 76,5\% dos 51 municípios da Região pesquisada) PMEs completos obtidos.

Após efetuadas todas as tentativas de obtenção dos PMEs da Região Administrativa de Marília, os 39 documentos coletados foram explorados, sistematizados e, por fim, analisados, com base na análise de conteúdo (FRANCO, 2008) e à luz do referencial teórico norteador da pesquisa, incialmente construído a partir da pesquisa bibliográfica empreendida, conforme abordado na próxima seção do trabalho.

\section{O cenário dos PMEs na Região Administrativa de Marília}

Localizada geograficamente no centro-oeste do Estado de São Paulo e intencionalmente selecionada pelo estudo em questão, a Região Administrativa de Marília abriga 51 municípios (Figura 1), a saber: Álvaro de Carvalho, Alvinlândia, Arco Íris, Assis, Bastos, Bernardino de Campos, Borá, Campos Novos Paulista, Cândido Mota, Canitar, Chavantes, Cruzália, Echaporã, Espírito Santo do Turvo, Fernão, Florínia, Gália, Garça, Herculândia, Iacri, Ibirarema, Ipaussu, João Ramalho, Júlio Mesquita, Lupércio, Lutécia, Maracaí, Marília, Ocauçu, Óleo, Oriente, Oscar Bressane, Ourinhos, Palmital, Paraguaçu Paulista, Parapuã, Pedrinhas Paulista, Platina, Pompéia, Quatá, Queiroz, Quintana, Ribeirão do Sul, Rinópolis, Salto Grande, Santa Cruz do Rio Pardo, São Pedro do Turvo, Tarumã, Timburi, Tupã e Vera Cruz. 
Figura 1 - Localização e composição da Região Administrativa de Marilia

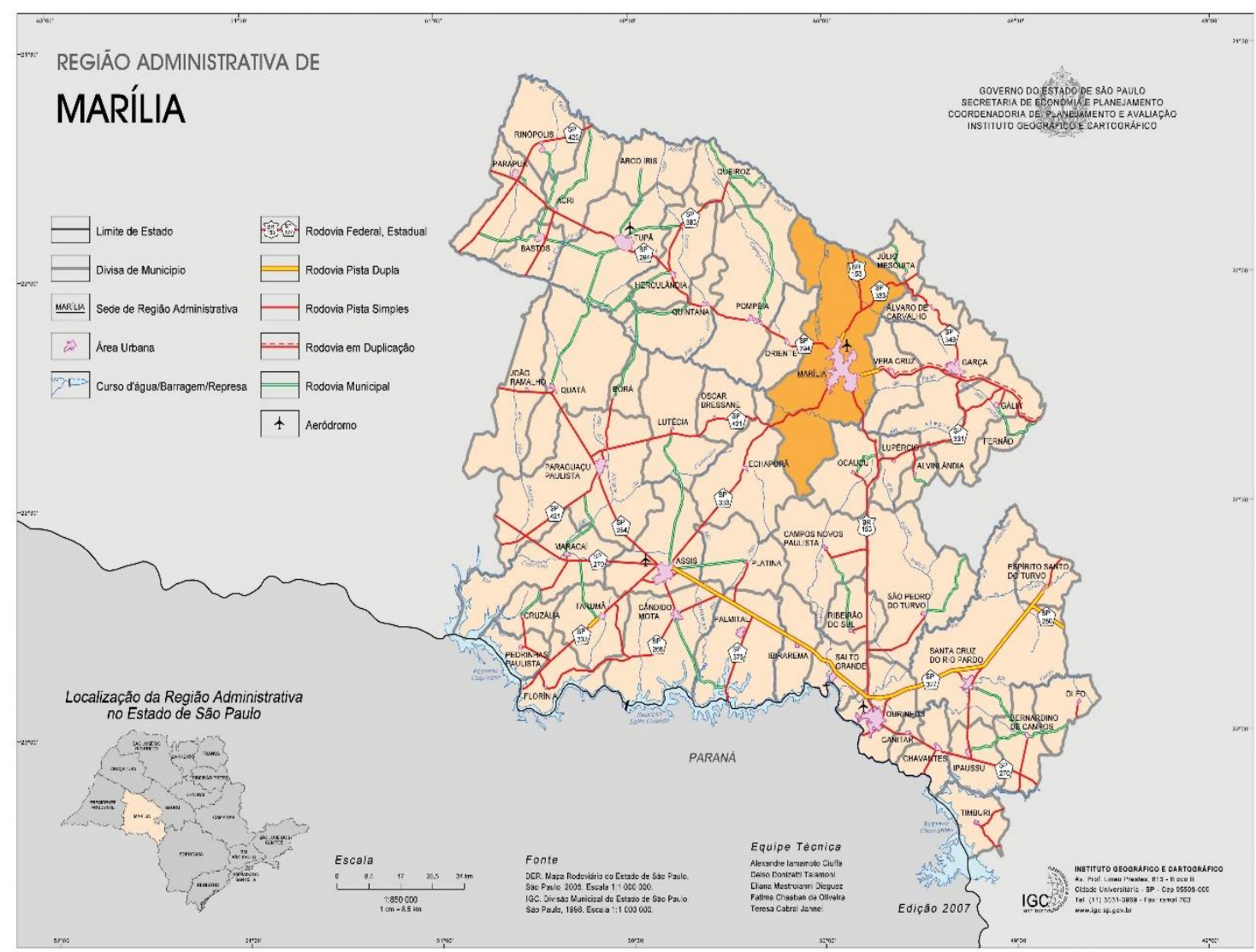

Fonte: Instituto Geográfico e Cartográfico - IGC. Disponível em

<http://www.igc.sp.gov.br/produtos/mapas_ra.aspx?>. Acesso em: 13 fev. 2019.

Na Região Administrativa de Marília a totalidade dos seus 51 municípios integrantes já aprovaram e possuem em vigência seus correspondentes PMEs, em consonância com o PNE 2014-2024.

Dos 39 PMEs colhidos e analisados pelo estudo em tela, observa-se a partir da Quadro 1 que: a expressiva maioria deles (32 ou 82\%) obteve aprovação dentro do prazo (até 24 de junho de 2015) estipulado pela Lei no 13.005/2014 (Arco Íris, Assis, Bastos, Bernardino de Campos, Campos Novos Paulista, Cândido Mota, Cruzália, Echaporã, Espírito Santo do Turvo, Fernão, Florínea, Garça, Herculândia, Ipaussu, João Ramalho, Júlio Mesquita, Lupércio, Maracaí, Marília, Óleo, Oscar Bressane, Ourinhos, Palmital, Pedrinhas Paulista, Quatá, Queiroz, Rinópolis, Salto Grande, Santa Cruz do Rio Pardo, São Pedro do Turvo, Tarumã e Vera Cruz); outros seis (ou 15,4\%) só vieram a ser aprovados após expirar o referido prazo, embora ainda dentro do limite anual de 2015 (Alvinlândia, Borá, Lutécia, Parapuã, Pompéia e Quintana); e apenas um (2,6\%) extrapolou de forma discrepante o prazo legalmente estabelecido, sendo aprovado somente no final de junho de 2016, ou seja, com um ano de atraso (Gália).

Quadro 1- PMEs da Região Administrativa de Marília: aprovação e vigência

\begin{tabular}{|l|l|l|}
\hline \multicolumn{1}{|c|}{ Município } & Lei do atual PME Aprovado & Período de vigência \\
\hline Alvinlândia & Lei $\mathrm{n}^{\mathbf{o}} 1.488 \mathrm{de} 05 / 08 / 2015$ & Não especificado \\
\hline
\end{tabular}




\begin{tabular}{|c|c|c|}
\hline Arco-Íris & Lei $n^{\circ} 0339$ de $23 / 04 / 2015$ & Não especificado \\
\hline Assis & Lei $^{\circ} 6.046$ de 24/06/2015 & De 2014 a 2024 \\
\hline Bastos & Lei $^{\circ}{ }^{\circ} .621$ de 16/06/2015 & Não especificado \\
\hline Bernardino de Campos & Lei $\mathrm{n}^{\circ} 1.933$ de $17 / 06 / 2015$ & De 2014 a 2024 \\
\hline Borá & Lei $n^{\circ} 709$ de $08 / 12 / 2015$ & De 2015 a 2024 \\
\hline Campos Novos Paulista & Lei $n^{\circ} 659$ de $23 / 06 / 2015$ & De 2015 a 2025 \\
\hline Cândido Mota & Lei $\mathrm{n}^{\circ} 2.346$ de $19 / 06 / 2015$ & De 2015 a 2025 \\
\hline Cruzália & Lei $n^{\circ} 594$ de 22/06/2015 & De 2015 a 2025 \\
\hline Echaporã & Lei $\mathrm{n}^{\circ} 1.872$ de $17 / 06 / 2015$ & De 2015 a 2025 \\
\hline Espírito Santo do Turvo & Lei $\mathrm{n}^{\circ} 759$ de $24 / 06 / 2015$ & De 2014 a 2024 \\
\hline Fernão & Lei $n^{\circ} 793$ de $22 / 06 / 2015$ & De 2015 a 2025 \\
\hline Florínea & Lei ${ }^{\circ} 559$ de $16 / 06 / 2015$ & De 2015 a 2025 \\
\hline Gália & Lei $\mathrm{n}^{\circ} 2.355$ de 28/06/2016 & De 2016 a 2026 \\
\hline Garça & Lei $n^{\circ} 4.998$ de $10 / 06 / 2015$ & De 2015 a 2025 \\
\hline Herculândia & Lei $n^{\circ} 2.942$ de 23/06/2015 & De 2015 a 2025 \\
\hline Ipaussu & Lei $n^{\circ} 145$ de $26 / 05 / 2015$ & De 2015 a 2025 \\
\hline João Ramalho & Lei $n^{\circ} 549$ de 17/06/2015 & De 2015 a 2025 \\
\hline Júlio Mesquita & Lei $\mathrm{n}^{\circ} 1.387$ de $23 / 06 / 2015$ & Não especificado \\
\hline Lupércio & Lei n $^{\circ} 44$ de 23/06/2015 & De 2015 a 2025 \\
\hline Lutécia & Lei $^{\circ} 21$ de 07/07/2015 & De 2015 a 2024 \\
\hline Maracaí & Lei $\mathrm{n}^{\circ} 2.076$ de 19/06/2015 & Não especificado \\
\hline Marilia & Lei $\mathrm{n}^{\circ} 7.824$ de 23/06/2015 & De 2015 a 2025 \\
\hline Óleo & Lei $\mathrm{n}^{\circ} 1.841$ de $22 / 06 / 2015$ & Não especificado \\
\hline Oscar Bressane & Lei $\mathrm{n}^{\circ} 1.349$ de $23 / 06 / 2015$ & Não especificado \\
\hline Ourinhos & Lei $n^{\circ} 6.227$ de $11 / 06 / 2015$ & De 2015 a 2025 \\
\hline Palmital & Lei $^{\circ} 2.695$ de $24 / 06 / 2015$ & De 2015 a 2025 \\
\hline Parapuã & Lei $\mathrm{n}^{\circ} 2.865$ de $26 / 06 / 2015$ & De 2015 a 2025 \\
\hline Pedrinhas Paulista & Lei $n^{\circ} 1.069$ de 23/06/2015 & De 2015 a 2025 \\
\hline Pompéia & Lei $\mathrm{n}^{\circ} 2.625$ de 22/12/2015 & De 2015 a 2025 \\
\hline Quatá & Lei $\mathrm{n}^{\circ} 2.946$ de 19/06/2015 & Não especificado \\
\hline Queiroz & Lei $\mathrm{n}^{\circ} 1.030$ de $19 / 06 / 2015$ & De 2015 a 2025 \\
\hline Quintana & Lei $n^{\circ} 2.194$ de $03 / 11 / 2015$ & Não especificado \\
\hline Rinópolis & Lei $\mathrm{n}^{\circ} 1.812$ de $17 / 06 / 2015$ & Não especificado \\
\hline Salto Grande & Lei $n^{\circ} 1.570$ de $16 / 06 / 2015$ & De 2015 a 2025 \\
\hline Santa Cruz do Rio Pardo & Lei $n^{\circ} 2.885$ de $24 / 06 / 2015$ & De 2015 a 2024 \\
\hline São Pedro do Turvo & Lei $n^{\circ} 2.258$ de $23 / 06 / 2015$ & Não especificado \\
\hline Tarumã & Lei $^{\circ} 1.168$ de $23 / 06 / 2015$ & De 2015 a 2025 \\
\hline Vera Cruz & Lei $^{\circ} 2.986$ de $22 / 06 / 2015$ & De 2015 a 2024 \\
\hline
\end{tabular}

Fonte: Elaboração própria. 
Pelo Quadro 1 constata-se, ainda, que os PMEs em análise majoritariamente (28 ou $71,8 \%$ ) explicitam em suas respectivas leis de criação e/ou anexo os anos de início e término de sua duração, ao passo que outros onze (ou 28,2\%) apresentam omissão acerca de tal aspecto.

Preponderantemente (22 ou 56,4\%), os PMEs das municipalidades vinculadas à Região Administrativa de Marília apresentam vigência decenal correspondente ao período de 2015 a $2025^{5}$ (Campos Novos Paulista, Cândido Mota, Cruzália, Echaporã, Fernão, Florínia, Gália, Garça, Herculândia, Ipaussu, João Ramalho, Lupércio, Marília, Ourinhos, Palmital, Parapuã, Pedrinhas Paulista, Pompéia, Queiroz, Salto Grande, Santa Cruz do Rio Pardo, Tarumã, e Vera Cruz).

Entretanto, verifica-se, também, que alguns PMEs apresentam datação de vigência equivocada: de 2014 a 2024 (Assis, Bernardino de Campos e Espírito Santo do Turvo), o que pode indicar uma tentativa de reprodução em âmbito local da estruturação e conteúdo do plano federal, numa perspectiva de cumprimento mais burocrático do planejamento educacional municipal, tal qual foi constatado por Silva e Oliveira (2016) ao analisarem uma amostra de 14 PMEs de municípios situados no noroeste do estado de São Paulo; e de 2015 a 2024 (Borá e Lutécia), período que sequer atinge a duração total de dez anos prevista para todos os Planos educacionais subnacionais.

Cumpre destacar que todos os PMEs em questão tiveram a respectiva vigência iniciada antes mesmo da aprovação do PEE de São Paulo, cujo considerável atraso da sua elaboração/tramitação, além de deixar os municípios paulistas desprovidos de uma "referência territorial" mais próxima do que a nacional para se "espelhar", fragiliza o planejamento educacional sistêmico e pode comprometer a plena consecução das metas nacionalmente fixadas para o decênio.

Aliás, dentre os fundamentos ou referenciais para os planos de educação, Bordignon (2014, p. 35) ressalta justamente a visão sistêmica. Em suas palavras:

\begin{abstract}
- visão sistêmica: um plano de educação, seja nacional, estadual ou municipal, além da contextualização em sua dimensão própria, deve ser referenciado, conectado na dimensão da nacionalidade, do todo nacional, ou seja: os diferentes planos não podem ser concebidos como sistemas fechados, mas abertos e articulados, trocando energias entre si, estabelecendo a sinergia no todo. É o espírito constitucional do regime de colaboração, que implica a definição de responsabilidades comuns, próprias e compartilhadas dos sistemas de ensino no todo nacional.
\end{abstract}

Como bem enfatiza a publicação "O Plano Municipal de Educação: caderno de orientações", elaborada pelo MEC em 2014 para auxiliar as municipalidades na importantíssima e inadiável tarefa de elaboração dos seus PMEs:

\begin{abstract}
Não se trata apenas de uma exigência legal: sem planos subnacionais formulados com qualidade técnica e participação social que os legitimem, o PNE não terá êxito. Os Planos Estaduais de Educação (PEEs) precisam ser imediatamente produzidos, debatidos e aprovados em sintonia com o PNE. E os Planos Municipais (PMEs), da mesma maneira que devem ser coerentes com o PNE, também devem estar alinhados aos PEEs dos estados a que pertencem. Para o cidadão, o PNE e os planos
\end{abstract}

\footnotetext{
${ }^{5}$ Excetuando-se Gália, cujo período de vigência é de 2016 a 2026 por conta do considerável atraso deste município na aprovação do seu PME.
}

Educação e Fronteiras On-Line, Dourados/MS, v.9, n.27, p.129-140, set. /dez. 2019 
de educação do estado e do município onde ele mora devem formar um conjunto coerente, integrado e articulado para que seus direitos sejam garantidos e o Brasil tenha educação com qualidade e para todos. (BRASIL, 2014b, p.6, grifos nosso).

Não obstante a dissintonia temporal e desalinhamento dos PMEs ao tardio PEE paulista, estes constituem-se em instrumento de suma importância para o planejamento e gestão das políticas públicas educacionais no âmbito das instâncias municipais. Como sabiamente aponta Bordignon (2009, p. 92):

\begin{abstract}
Quando o município não tem plano fica à mercê de ações episódicas que, mesmo planejadas caso a caso, representam improvisações. Sem plano municipal não há visão de Estado nas ações, não há caminho a percorrer, mas apenas passos ao sabor das circunstâncias de cada Governo.
\end{abstract}

Diante do longo histórico de descontinuidades dos planos e políticas educacionais no Brasil, mesmo depois de aprovados:

[...] é importante que os planos de educação municipais sejam também foco de estudos e acompanhamento, pois não estão livres de ser manipulados e de servir a propósitos que não a garantia de uma escola pública, laica e de qualidade para todos (SILVA; MURANAKA, 2017, p. 244).

Portanto, uma vez aprovados e vigentes os PMEs no âmbito das localidades jurisdicionadas à Região Administrativa de Marília, o desafio premente consiste em implementar, monitorar e avaliar tais planos.

\title{
Monitoramento e avaliação nos PMEs: o caso da Região Administrativa de Marília
}

Além de estipular monitoramento contínuo e avaliações periódicas acerca da execução e cumprimento das metas e estratégias do PNE 2014-2024 e de seus similares em nível estadual, distrital e municipal (Art. $5^{\circ}$ e Art. $7^{\circ}, \S 3^{\circ}$ ), a Lei ${ }^{\circ} 13.005 / 2014$ foi além do PNE I e avançou ao definir com maior precisão as instâncias responsáveis pela realização de tal processo. No caso dos municípios, as instâncias seriam:

\author{
- Secretaria Municipal de Educação; \\ - Comissão de Educação da Câmara ou a própria Câmara; \\ - Conselho Municipal de Educação; \\ - Fórum Municipal de Educação (OLIVEIRA et al., 2016, p. 31).
}

Dos 39 PMEs perscrutados, a quase totalidade deles (38 ou 97,4\%) prevê explicitamente sistemáticas de monitoramento e avaliação, em claro alinhamento ao preconizado pela Lei do PNE vigente e documento orientador do MEC (BRASIL, 2014b) concernente à temática. Em contrapartida, somente um (ou 2,6\%) se furta a fazer tal menção.

Daquele montante de 38 PMEs com previsão de monitoramento e avaliação do plano local, em seis $(15,8 \%)$ deles registra-se alusão a tais ações exclusivamente no corpo da lei de criação do PME, em outro (1 ou 2,6\%) a referência se faz presente unicamente no anexo da lei (o plano propriamente dito) e, na absoluta maioria (31 ou 81,6\%) deles as menções ao 
monitoramento e avaliação dos planos subnacionais comparecem tanto no corpo da lei quanto no seu respectivo anexo.

A propósito, em 18 (ou 47,4\%) deles nota-se, inclusive, a existência de seção específica no anexo do PME destinada à temática em abordagem, predominantemente denominada de "Acompanhamento e Avaliação do Plano", o que sugere certa dificuldade das municipalidades correspondentes "[...] para se afastar do modelo metodológico adotado na construção do PNE 2001-2010 [...]”" (MENEZES; SOUZA, 2018, p. 627).

No que se refere ao monitoramento dos PMEs, é possível identificar que em cerca de metade (19 ou 48,7\%) das fontes documentais examinadas não há determinação de sua periodicidade. Entretanto, tal qual o recomendado pelo Caderno de Orientações editado pelo MEC (BRASIL, 2014b), outra parte significativa (16 ou 41\%) dos PMEs analisados define uma regularidade anual, seguida por 4 (ou 10,3\%) cuja opção temporal adotada é a bienal.

No que tange à periodicidade prevista para a realização das avaliações dos planos educacionais, no conjunto dos PMEs analisados observa-se que ela varia de um a cinco anos, a saber: anual (4 ou 10,3\%); bienal (13 ou 33,3\%); trienal (3 ou 7,7\%); quadrienal $(7,7 \%)$; quinquenal (11 ou 28,2\%); além de 5 (ou 12,8\%) PMEs que não fizeram qualquer alusão temporal relativa à avaliação do planejamento decenal municipal.

Se por um lado, a prevalência da avaliação bienal (13 ou 33,3\%) nos planos pesquisados destoa da orientação federal de realizá-la trienalmente (BRASIL, 2014b), por outro, tal

[...] temporalidade julga-se de maior produtividade para esse tipo de planejamento educacional, pois permitem, em um espaço de dez anos, maior número de intervenções, embora demandando, em tempo mais reduzidos, maior atenção sobre o acompanhamento da implantação do plano por parte do poder público e da sociedade civil local (SOUZA; ALCÂNTARA, 2016, p. 207).

Ademais, avaliações mais longevas, como a quinquenal (11 ou 28,2\%), podem ser contraproducentes em caso de uma possível necessidade de replanejamento substancial, pois uma "[...] uma avaliação na metade da vigência, ou no final [do plano, pouco contribui] para corrigir o rumo perdido" (BORDIGNON, 2014, p. 47).

Quanto às instâncias responsáveis pelo monitoramento e avaliação dos PMEs, os documentos examinados fazem majoritária referência ao Conselho Municipal de Educação (CME) (27 ou 69,2\%) e à Secretaria Municipal de Educação (SME) ou órgão equivalente (25 ou $64,1 \%$ ) como principais condutores de tal processo em nível local. Deste modo, divergindo positivamente dos achados de outro estudo (SOUZA; ALCÂNTARA, 2016) que tomou por base empírica dez PMEs de localidades fluminenses para examinar o papel do CME na discussão, elaboração, acompanhamento e avaliação dos mesmos, os números apresentados aqui indicam claramente uma centralidade exercida compartilhadamente entre CME e SME, configurando-se num grande avanço ao superar a costumeira tendência de concentrar a referida responsabilidade tão somente nas mãos do órgão executivo do sistema municipal de ensino e alijar o correspondente órgão colegiado da mencionada atribuição.

Ao reconhecer o potencial do CME no controle social das políticas públicas educacionais locais, uma vez que constitui-se em espaço privilegiado para a participação da sociedade civil na sua gestão, Monlevade (2004, p. 40) pontua que: 
O papel de dar o comando, de coordenar a elaboração, de executar as ações necessárias à construção e posterior execução e avaliação do PME é da Secretaria Municipal de Educação (SME), [...] mas, havendo um Conselho Municipal de Educação, com poder normativo ou somente consultivo, é dele o papel primordial de inspirar, incentivar, colaborar e orientar todo o processo de elaboração, execução e avaliação do PME.

Não obstante o aludido avanço, em dissintonia quanto aos espaços institucionais definidos em nível nacional para a efetuação do monitoramento e da avaliação, os PMEs sob exame secundarizam a participação do Fórum Municipal de Educação (FME) (13 ou 33,3\%) e da Câmara Municipal de Vereadores (7 ou 17, 9\%), de modo a deslegitimar sua competência no tocante a tal empreitada.

Espaços de interlocução entre a sociedade civil e o governo e fundamentais para a efetivação da gestão democrática da educação (DOURADO, 2017), os FMEs “[...] assumem um importante papel na medida em que articulam os diferentes anseios com vistas ao planejamento participativo na formulação dos planos decenais de educação e em seu monitoramento" (SCAFF; OLIVEIRA; ARANDA, 2018, p. 138).

Cabe destacar, ainda, que parte expressiva (18 ou 46,2\%) das municipalidades pesquisadas, na contramão das orientações federais, não faz qualquer menção nos seus PMEs à constituição de Comissão de Monitoramento e Avaliação dos planos locais, cuja existência é imprescindível para o êxito do processo em tela.

\section{CONSIDERAÇÕES FINAIS}

O estudo desenvolvido acerca da previsão de monitoramento e avaliação nos PMEs da Região Administrativa de Marília permitiu revelar aspectos tanto positivos quanto preocupantes, conforme retrospectiva e sinteticamente recuperado: constatou-se que a quase totalidade das municipalidades investigadas estabeleceu explicitamente nos seus respectivos PMEs sistemáticas de monitoramento e avaliação, em claro alinhamento ao PNE vigente, tanto no corpo da Lei do PME quanto no seu anexo (o plano propriamente dito). Entretanto, observou-se, também, que cerca de metade dos PMEs não determinou a periodicidade concernente ao monitoramento e neles prevalece a avaliação bienal, destoando, portanto, das orientações oficiais federais atinentes ao referido processo de monitoramento (anual) e avaliação (trienal) dos planos subnacionais de educação. Evidenciou-se, ainda, que, de forma análoga as ações de monitoramento e avaliação propostas para o plano de âmbito nacional, os PMEs fazem referência aos CMEs e SMEs (ou órgão equivalente) como principais instâncias responsáveis pela condução de tal processo em nível local, mas, simultânea e majoritariamente, secundarizam a correspondente participação do Fórum Municipal de Educação e da Câmara Municipal de Vereadores, cuja frequência de menções é consideravelmente menor. Por fim, revelou-se que parte expressiva das municipalidades, na contramão dos documentos federais, não faz qualquer alusão nos seus PMEs à constituição de Comissão de Monitoramento e Avaliação dos planos locais, cuja existência é crucial para o êxito do processo em tela.

Depreende-se, portanto, a partir do conjunto das fontes documentais analisadas, que se por um lado as municipalidades abrangidas pelo presente estudo muito já caminharam para que seus PMEs venham a ter sua implementação efetivamente monitorada e avaliada, por outro permanece ainda o desafio de se contemplar um maior envolvimento da sociedade e dos múltiplos canais representativos nas questões atinentes ao planejamento e gestão da educação 
municipal, a fim de que esta possa plenamente alcançar a tão almejada gestão democrática e a qualidade social.

Indubitavelmente, para que os PMEs se distanciem cada vez mais de um mero cumprimento burocrático e se configurem verdadeiramente como epicentro das políticas educacionais locais, a ampla e permanente mobilização e participação da sociedade civil organizada se faz imprescindível.

\section{REFERÊNCIAS}

ALVES, Edson Ferreira. Universalização da aprovação de planos de educação por estados e municípios: o que vem depois? In: XXVIII Simpósio de Política e Administração da Educação, 2017, João Pessoa, PB. Anais...UFG: ANPAE, 2017, v. 45. p. 2307-2318.

ANTUNES, Marina Ferreira de Souza. Plano Municipal de Educação de Uberlândia monitoramento e avaliação: desafios para a valorização da carreira docente. Revista Educação e Políticas em Debate, v. 8, n. 1, p. 19-36, jan./abr. 2019.

BORDIGNON, Genuíno. Gestão da educação no município: sistema, conselho e plano. São Paulo: Editora e Livraria Instituto Paulo Freire, 2009.

Caminhar da educação brasileira: muitos planos, pouco planejamento. In: SOUZA, Donaldo Bello de; MARTINS, Angela Maria (Orgs.). Planos de Educação no Brasil: planejamento, políticas, práticas. São Paulo: Edições Loyola, 2014. p. 29-53.

BRASIL. Lei $n^{o} 13.005$, de 25 de junho de 2014. Aprova o Plano Nacional de Educação e dá outras providências. Diário Oficial da União, Brasília, DF, 26. jun. 2014. Seção 1, p.01. 2014a.

Ministério da Educação. Secretaria de Articulação com os Sistemas de Ensino (SASE). O Plano Municipal de Educação: caderno de orientações. Brasília: MEC, 2014b.

DOURADO, Luiz Fernandes. Plano Nacional de Educação: o epicentro das políticas de estado para a educação brasileira. Goiânia: Editora da Imprensa Universitária/ANPAE, 2017.

DOURADO, Luiz Fernandes; GROSSI JUNIOR, Geraldo; FURTADO, Roberval Ângelo. Monitoramento e avaliação dos planos de educação: breves contribuições. $R B P A E$, v. 32 , n. 2 , p. 449 - 461 maio/ago. 2016.

FRANCO, Maria Laura Puglisi Barbosa. Análise de conteúdo. 3. ed. Brasília: Líber Livro, 2008.

LÜDKE, Menga; ANDRÉ, Marli Eliza D. A. Pesquisa em educação: abordagens qualitativas. São Paulo: EPU, 1986.

MARCONI, Marina de Andrade; LAKATOS, Eva Maria. Metodologia do trabalho científico: procedimentos básicos, pesquisa bibliográfica, projeto e relatório, publicações e trabalhos científicos. 7. ed. 6. reimpr. São Paulo: Atlas, 2011. 
MENEZES, Janaína Specht da Silva; SOUZA, Donaldo Bello de. Monitoramento e avaliação nos Planos Estaduais de Educação consoantes ao novo PNE. PRÓ-POSIÇÕES, v. 29, p. 614639, 2018.

MONLEVADE, João Antônio. A importância do Conselho Municipal de Educação na elaboração, implantação e acompanhamento da execução do Plano Municipal de Educação. In: BRASIL. Ministério da Educação. Secretaria de Educação Básica. Programa Nacional de Capacitação de Conselheiros Municipais de Educação Pró-Conselho: caderno de referência. Brasília, DF: MEC/SEB, 2004.

NASCIMENTO, Gilvânia da Conceição; GROSSI JUNIOR, Geraldo; PEREIRA, Jhonata Moreira. Planos Municipais de Educação: perfil dos municípios que não possuíam plano municipal de educação no segundo ano de vigência da Lei n. 13.005/14. Revista Exitus, Santarém/PA, v. 7, n. 1, p. 108-130, jan./abr. 2017.

OLIVEIRA, João Ferreira et al. Planos Estaduais, Distrital e Municipais de Educação: monitoramento e avaliação - Caderno Temático ANPAE 4. Camaragibe, PE: CCS Gráfica e Editora, 2016.

SCAFF, Elisangela Alves da Silva; OLIVEIRA, Marli dos Santos de; ARANDA, Flávia Paula Nogueira. Planejamento educacional e poder local na elaboração dos planos municipais de educação. Quaestio, Sorocaba, SP, v. 20, n. 1, p. 133-147, abr. 2018.

SCAFF, Elisangela Alves da Silva; OLIVEIRA Marli dos Santos de. Planos decenais de educação: sistematização do monitoramento e avaliação nos cenários estadual e municipal. Série-Estudos, Campo Grande, MS, v. 23, n. 47, p. 141-162, jan./abr. 2018.

SILVA, Leandro Vitoriano da; OLIVEIRA, Maria Eliza Nogueira. O Plano Municipal de Educação: da autonomia construída à autonomia decretada. Revista Teias, Rio de Janeiro, v. 17, n. 47, p. 107-123, out./dez. 2016.

SILVA, Mariana Aparecida da; MURANAKA, Maria Aparecida Segatto. Uma análise do processo de elaboração do plano municipal de educação de Rio Claro-SP. Educação: Teoria e Prática, Rio Claro, SP, v. 27, n.55, p.244-261, maio/ago. 2017.

SOUZA, Donaldo Bello de; ALCÂNTARA, Alzira Batalha. O lugar dos Conselhos Municipais de Educação nos PMEs relativos ao PNE 2001-2010. Revista Educação em Questão, Natal, v.54, n.40, p. 191-219, jan./abr. 2016.

Recebido em: 09/05/2019

Aprovado em: 12/07/2019 